\title{
Heart Valve Surgery Today
}

\author{
Indications, Operative Technique, and Selected Aspects of \\ Postoperative Care in Acquired Valvular Heart Disease
}

Hans Joachim Geißler, Christian Schlensak, Michael Südkamp, Friedhelm Beyersdorf

\section{SUMMARY}

Background: Surgery plays a central role in the management of acquired valvular heart disease. The optimal diagnostic evaluation, surgical treatment, and postoperative care of these patients are only possible through a cooperative effort of the primary care physician, the cardiologist, and the cardiac surgeon.

Methods: The literature was selectively searched for information on surgical indications, operative techniques, and postoperative care in acquired valvular heart disease. Evidence-based guidelines and treatment recommendations were also taken into account.

Results: A wide variety of techniques and implants are now available for the surgical treatment of acquired valvular heart disease. If they are used in evidence-based fashion, the perioperative mortality is low and the long-term outcome is favorable.

Conclusions: The volume of surgery for acquired valvular heart disease in Germany has increased substantially in recent years, from 25495 cases in 2002 (corresponding to $26.5 \%$ of all heart operations in that year) to 33412 in 2007 (36.5\% of all heart operations). The causes for this include both demographic changes and the availability of new, less invasive surgical techniques that yield better results in elderly and/or multimorbid patients. Because of these new techniques, the indications for surgery have widened, while the results have remained favorable.

$$
\text { Dtsch Arztebl Int 2009; 106(13): 224-34 }
$$$$
\text { DOl: 10.3238/arztebl.2009.0224 }
$$

Key words: cardiac surgery, valvular heart disease, cardiac valve replacement, cardiac valve reconstruction, endocarditis

Abteilung für Herz- und Gefäßchirurgie, Chirurgische Klinik, Universitätsklinikum Freiburg: PD Dr. med. Geißler, Prof. Dr. med. Schlensak, PD Dr. med. Südkamp, Prof. Dr. med. Dr. h. c. Beyersdorf
M ore than 30000 patients currently undergo surgery for acquired valvular heart disease in Germany each year (1), of whom nearly 17,000 have disease of a single valve, more than 3000 have disease of two or three valves, and roughly 12000 undergo a valvular procedure in combination with an aortocoronary bypass operation. The aortic and mitral valves are the more commonly affected ones; the pulmonary valve, in contrast, is affected almost exclusively by congenital diseases, which will not be discussed in this article. Surgical procedures on the tricuspid valve are also rare, accounting for only $2.6 \%$ of the isolated, single-valve operations performed in 2007.

The learning objectives of this article are that the reader should

- know the indications for surgical treatment of acquired heart valve diseases,

- be acquainted with the surgical techniques used to treat acquired heart valve diseases, and

- be able to perform appropriate endocarditis prevention in patients that have undergone heart valve surgery, in accordance with current guidelines.

The following overview of the surgical indications for acquired heart valve diseases is based on the current guidelines of the German Cardiological Society (Deutsche Gesellschaft für Kardiologie) (2). Corresponding guidelines have also been issued by the European Society of Cardiology (e1) and by the American Heart Association in collaboration with the American College of Cardiology (e2)

\section{Aortic stenosis}

The calcific form of aortic stenosis is by far the most common type in industrialized countries, with an incidence of $2 \%$ to $9 \%$ among persons over age 65 . The post-rheumatic form, in contrast, has become rare. Concentric left-heart hypertrophy with diastolic

\section{Acquired valvular heart disease}

Acquired valvular heart disease mainly affects the aortic and mitral valves, while the pulmonary valve is affected almost exclusively by congenital defects. 
dysfunction is the typical finding in longstanding aortic stenosis. Aortic stenosis takes a progressive course, with a decrease in the valvular opening area by roughly $0.1 \mathrm{~cm}^{2}$ per year, although marked interindividual variability has been observed (e3).

In the asymptomatic phase of the disease, the risk of sudden cardiac death is less than $1 \%$ per year. Patients with symptomatic aortic stenosis, on the other hand, will survive untreated for an average of only two to three years from the onset of cardiac symptoms. If aortic stenosis is clinically suspected and auscultation reveals the typical findings, the diagnosis can be confirmed by Doppler echocardiography.

Aortic stenosis is said to be severe when a mean pressure gradient higher than $50 \mathrm{~mm} \mathrm{Hg}$ and a valve opening area less than 0.75 to $1.0 \mathrm{~cm}^{2}$ (corresponding to less than $0.6 \mathrm{~cm}^{2}$ per square meter of body surface area) are measured in the setting of a normal stroke volume. The determination of the degree of stenosis in patients with reduced left ventricular function presents a particular diagnostic challenge, because falsely low gradients can be measured in this situation (e4).

\section{Surgical indications and results}

As medical therapy has essentially no influence on the course of the disease, valve replacement is the only option for effective and definitive treatment. There is a class I recommendation for operative aortic valve replacement for patients with severe, symptomatic aortic stenosis. For patients with severe, but asymptomatic aortic stenosis and impaired left ventricular function, rapid progression of aortic stenosis, or an abnormal exercise test, the recommendation for aortic valve replacement is in class IIa or IIb (table 1). Surgery is considered to be indicated in view of the fundamentally progressive nature of the valve condition and the low in-hospital lethality of elective aortic valve replacement surgery (ca. $1.5 \%$ to $2.5 \%$ ) (e5, e6). Thus, the objective should be to operate before further factors arise that elevate the probability of death, such as worsening left ventricular function or a sudden need for emergency surgery. A special class of patients consists of those who are to undergo aortocoronary bypass operations and have also been found to have moderately severe aortic stenosis, which would not, in itself, constitute an indication for surgery. In this situation, the key consideration is that a second operation for aortic valve replacement after successful bypass surgery would confer a much higher operative risk. The risk

\section{Aortic stenosis}

The calcific form of aortic stenosis is by far the most common type of acquired heart valve disease in industrialized countries, with an incidence of $2 \%$ to $9 \%$ among persons over age 65 .

\section{TABLE 1}

\section{Recommendation grades and evidence levels in evidence-based} medicine*1

\begin{tabular}{l|l}
$\begin{array}{l}\text { Recommendation } \\
\text { grade }\end{array}$ & Definition \\
\hline I & $\begin{array}{l}\text { Evidence or general agreement that a type of treatment or } \\
\text { diagnostic measure is effective, useful, or beneficial }\end{array}$ \\
\hline II & $\begin{array}{l}\text { Conflicting evidence and/or conflicting expert opinion as to the } \\
\text { usefulness/effectiveness of a type of treatment or diagnostic } \\
\text { measure }\end{array}$ \\
\hline Ila & $\begin{array}{l}\text { The evidence and expert opinion favor the usefulness and } \\
\text { effectiveness of the measure in question }\end{array}$ \\
\hline IIb & $\begin{array}{l}\text { The usefulness and effectiveness of the measure in question } \\
\text { are less well supported by the evidence and expert opinion }\end{array}$ \\
\hline Evidence level & Definition \\
\hline A & $\begin{array}{l}\text { The recommendation is supported by at least two randomized } \\
\text { studies }\end{array}$ \\
\hline B & $\begin{array}{l}\text { The recommendation is supported by a single randomized } \\
\text { study and/or a meta-analysis of nonrandomized studies }\end{array}$ \\
\hline C & Expert consensus based on studies and clinical experience \\
\hline & \\
\hline
\end{tabular}

${ }^{\star 1}$ Modified from (2)

should be assessed individually for each patient; the expected progression of the aortic valve disease and the patient's life expectancy should be taken into account, so that a high-risk reoperation can be avoided whenever possible.

\section{Aortic regurgitation}

Aortic regurgitation is much rarer than calcific aortic stenosis. Its common causes include aorto-annular ectasia and the various types of bicuspid aortic valve (3). Bacterial endocarditis and valvular defects of rheumatic origin are much rarer causes. Pure aortic regurgitation must be differentiated from the valvular regurgitation that accompanies calcific aortic stenosis. When the latter entity is treated, it is generally the severity of the stenosis that determines the choice of therapy.

Untreated aortic regurgitation causes a progressive dilated cardiomyopathy through volume loading of the left ventricle, with resulting impairment of left ventricular contractility, which, in the late phase, leads to left heart failure. Chronic aortic regurgitation does not become symptomatic until its late phase, with dyspnea 
Indications for surgery in aortic, mitral, and tricuspid valve disease (after [2])

\begin{tabular}{|c|c|c|}
\hline \multirow{2}{*}{$\begin{array}{l}\text { Aortic stenosis } \\
\text { Symptomatic patient with severe aortic stenosis }\end{array}$} & \multicolumn{2}{|c|}{$\begin{array}{l}\text { Recommendation grade } \\
\text { and evidence level }\end{array}$} \\
\hline & I & B \\
\hline $\begin{array}{l}\text { Asymptomatic patient with severe aortic stenosis } \\
\text { and } \\
\text { reduced } \operatorname{LVEF}(<50 \%) \\
\text { or } \\
\text { moderately to severely calcified valve and rapid hemodynamic progression } \\
\text { or } \\
\text { pathological exercise test with symptoms }\end{array}$ & Ila & C \\
\hline $\begin{array}{l}\text { Asymptomatic patient with severe aortic stenosis and pathological exercise test without symptoms } \\
\text { (abnormal blood pressure regulation, ST/T-wave changes, VES) }\end{array}$ & Ilb & C \\
\hline Demonstration of ventricular salvoes/tachycardia & $\mathrm{llb}$ & C \\
\hline \multicolumn{3}{|l|}{ Aortic regurgitation } \\
\hline Symptomatic patient & I & B \\
\hline Asymptomatic patient with LVEF $<50 \%$ and/or end-systolic diameter $>50 \mathrm{~mm}$ & I & B \\
\hline $\begin{array}{l}\text { Asymptomatic patient with LVEF } 50 \%-60 \% \text { and end-systolic diameter } 45-50 \mathrm{~mm} \text {, } \\
\text { if symptoms arise during exercise test }\end{array}$ & Ila & C \\
\hline \multicolumn{3}{|l|}{ Mitral stenosis } \\
\hline $\begin{array}{l}\text { Markedly symptomatic patient (NYHA III-IV), valvuloplasty not possible, } \\
\text { mitral valve opening area }<1.5 \mathrm{~cm}^{2}\end{array}$ & I & B \\
\hline Not markedly symptomatic patient (NYHA I-II), valvuloplasty not possible, mitral valve opening area $<1.0 \mathrm{~cm}^{2}$ & I & B \\
\hline \multicolumn{3}{|l|}{ Mitral regurgitation } \\
\hline Symptomatic patient with severe chronic MR, LVEF > 30\% & I & B \\
\hline Symptomatic patient with severe chronic MR, LVEF $<30 \%$, if reconstruction is possible & Ila & C \\
\hline $\begin{array}{l}\text { Asymptomatic patient with severe chronic MR, LVEF }<60 \% \text { and/or } \\
\text { end-systolic LV diameter }>45 \mathrm{~mm}\end{array}$ & I & B \\
\hline $\begin{array}{l}\text { Asymptomatic patient with severe, chronic MR } \\
\text { and } \\
\text { paroxysmal or newly arisen persistent atrial fibrillation } \\
\text { or } \\
\text { systolic pulmonary arterial pressure at rest }<50 \mathrm{~mm} \mathrm{Hg} \\
\text { or } \\
\text { LVEF }>60 \% \text { and end-systolic LV diameter }>45 \mathrm{~mm} \text {, } \\
\text { but lack of contractile reserve on exercise testing }\end{array}$ & Ila & C \\
\hline \multicolumn{3}{|l|}{ Tricuspid stenosis } \\
\hline Mean pressure gradient $>5 \mathrm{~mm} \mathrm{Hg}$, and another cardiac surgical procedure is being performed simultaneously & Ila & C \\
\hline Mean pressure gradient $>5 \mathrm{~mm} \mathrm{Hg}$ and severe right heart failure under maximal treatment & Ila & C \\
\hline \multicolumn{3}{|l|}{ Tricuspid regurgitation } \\
\hline Severe regurgitation, as long as another valvular procedure is needed simultaneously & Ila & C \\
\hline Severe regurgitation and severe right heart failure & Ila & $C$ \\
\hline
\end{tabular}

\section{Indications for surgery in aortic valve disease (class I-B recommendation)}

- Symptomatic aortic stenosis

- Symptomatic aortic regurgitation
- Asymptomatic aortic regurgitation with LVEF $<50 \%$ and/or end-systolic LV diameter $>50 \mathrm{~mm}$ 
as the main manifestation. The diagnosis of aortic regurgitation, like that of aortic stenosis, can be confirmed by Doppler echocardiography. The goal of the conservative medical treatment of aortic regurgitation is to reduce afterload, but the putative long-term benefits of afterload reduction for the course of the disease (potentially slowed progression, with postponement of the need for surgery) cannot be definitively assessed on the basis of the currently available data.

\section{Surgical indications}

Patients with symptomatic aortic regurgitation (as with symptomatic aortic stenosis) unequivocally need surgery. Equally uncontroversial is the indication for surgery in asymptomatic patients whose left ventricular function is already restricted to the point that their left ventricular ejection fraction is below $50 \%$ (table 2). For asymptomatic patients with intact left ventricular function, but marked dilatation of the left ventricle (end-systolic diameter greater than $50 \mathrm{~mm}$ ), there is a class IIa recommendation for surgery. In certain situations-most importantly, bicuspid valve and aortoannular dilatation-there is an opportunity for aortic valve reconstruction (4).

\section{Mitral stenosis}

The most common cause of mitral stenosis is rheumatic carditis. It has been estimated that undiagnosed or inadequately treated rheumatic fever leads to mitral valve disease in $40 \%$ of cases. The common symptoms of mitral stenosis are exertional dyspnea and tachycardic atrial fibrillation. If the echocardiographically measured mitral valve opening area is less than $2.5 \mathrm{~cm}^{2}$, clinically relevant mitral stenosis is present.

\section{Surgical indications and results}

Alongside surgery for mitral stenosis, an option also exists for interventional treatment by percutaneous balloon commissurotomy. Surgical or interventional treatment is considered to be indicated when the stenosis is symptomatic and the mitral valve area is less than $1.5 \mathrm{~cm}^{2}$. For asymptomatic patients with a valve opening area less than $1.5 \mathrm{~cm}^{2}$, surgical treatment is indicated only in the presence of pulmonary hypertension (table 2 ). Surgery is to be preferred over percutaneous balloon commissurotomy when

- the valvular morphology is unsuitable (usually because of calcification of the valve),

- there are thrombi in the left atrium,
- there is a clinically relevant degree of mitral regurgitation (danger of worsening after percutaneous balloon commissurotomy), or

- another finding requiring surgery is simultaneously present (e.g., tricuspid regurgitation).

The two available surgical procedures are mitral valve reconstruction (commissurotomy) and mitral valve replacement. The definitive decision which of these is to be performed can often only be made intraoperatively. If atrial fibrillation is concomitantly present, as is often the case, the valve operation can be combined with an atrial ablation procedure. The classical MAZE operation for atrial ablation has been largely abandoned because of its invasiveness, but a number of alternative techniques are currently available that employ radio waves, cold, or high-frequency ultrasound; these techniques can be used successfully for ablation without any elevation of the operative lethality (5-7).

\section{Mitral regurgitation}

Mitral regurgitation is the second most common acquired heart valve disease for which surgery is performed, after aortic stenosis. Its main causes are degenerative valvular changes, ischemic wall motion abnormalities of the left ventricle, and left ventricular dilatation in dilated cardiomyopathy. Infectious endocarditis and rheumatic fever are rarer causes.

The main clinical manifestations of mitral regurgitation are exertional dyspnea and atrial fibrillation. The echocardiographic assessment of the severity of mitral regurgitation is a complex matter and often requires a transesophageal echocardiographic study. Transesophageal echocardiography (TEE) is also indispensable for the determination whether the mitral valve can be surgically reconstructed.

\section{Surgical indications and results}

In the last few years, the surgical treatment of mitral regurgitation has undergone a paradigm shift. As recently as ten years ago, the valve was replaced in about $80 \%$ of cases; today, more than half of all mitral valves that are operated upon are reconstructed, rather than replaced. According to the current statistics of the German Society for Thoracic and Cardiovascular Surgery, the in-hospital lethality of mitral valve replacement is $8.4 \%$ across Germany, while the corresponding figure for mitral valve reconstruction is $2.4 \%$ (1). This difference in lethality is also taken into account in the current guidelines regarding surgical indications. Thus,

\section{Mitral stenosis}

The most common cause of mitral stenosis is rheumatic carditis.
The main causes of mitral regurgitation are

- degenerative valvular changes,

- ischemic wall motion disturbances of the left ventricle, and

- left ventricular dilatation in dilated cardiomyopathy. 
there is a class I-B recommendation for surgery for patients with severe, symptomatic mitral regurgitation but without high-grade impairment of left ventricular function (LVEF > 30\%). On the other hand, for patients with the same constellation of findings but with highgrade impairment of left ventricular function $(\mathrm{LVEF}<$ $30 \%$ ), surgery is recommended only if the valve can be reconstructed (class IIa-B recommendation). Surgery is recommended for some patients with severe, but asymptomatic mitral regurgitation, depending on their left ventricular function, left ventricular diameter, concomitant atrial fibrillation, pulmonary arterial pressure, and lack of contractile reserve on exertion; the recommendation is then class I-B or class IIa-C (table 2 ).

Surgery for mitral valve prolapse syndrome is indicated only when severe mitral regurgitation is present. The indication criteria are then identical to those for mitral regurgitation of other causes. An increasing number of combined procedures are being performed in which mitral regurgitation is treated along with another, concomitantly present cardiac disease, most commonly coronary heart disease. In the latter situation, there is a class IIa-B recommendation for combined surgery; in such cases, valve reconstruction is to be preferred to valve replacement wherever possible.

\section{Tricuspid stenosis and tricuspid regurgitation}

Tricuspid stenosis is rare and usually of rheumatic origin. It commonly occurs in combination with other valvular diseases. It is said to be clinically relevant if the mean pressure gradient across the tricuspid valve is 5 $\mathrm{mm} \mathrm{Hg}$ or more. Tricuspid regurgitation is more common than stenosis and can be either primary, i.e., due to morphological changes of the valve itself, or secondary, as the result of right heart dilatation in response to elevated right ventricular pressure.

\section{Surgical indications and results}

Surgery is indicated for symptomatic tricuspid stenosis with severe right heart failure. In principle, valve reconstruction is preferred to valve replacement, because the risk of thromboembolism is high with valvular prostheses in the tricuspid position. A further disadvantage is that the insertion of a transvenous pacemaker system is no longer possible once the tricuspid valve has been replaced. For patients without any manifest right heart failure, surgery of the tricuspid valve is indicated if another heart valve is being operated on at the same time (class IIa-C recommendation). In
Germany, in the year 2007, three times as many operations were performed on the tricuspid valve in combination with one or more other valves than on the tricuspid valve alone(1); mitral and tricuspid valve surgery was the most common combination. The in-hospital lethality of isolated tricuspid valve procedures is roughly $10 \%$, and thus markedly higher than that of isolated procedures on the other heart valves (1). Interestingly, the lethality of combined procedures involving the tricuspid valve and one or more other valves is also roughly $10 \%$, i.e., no higher than that of tricuspid valve surgery alone (1).

\section{Heart valve surgery in infectious endocarditis}

Infectious endocarditis remains an epidemiologically and clinically important disease, with an incidence of 30 cases per million persons per year and an overall lethality of roughly $18 \%$ (8). Important determinants of outcome include timely diagnosis, the identification of the infectious organism, and appropriately tailored antibiotic treatment. The treatment of infectious endocarditis is mainly conservative. If endocarditis leads to high-grade heart valve regurgitation, usually affecting the aortic and/or mitral valves, any surgery that is performed should ideally take place only after the endocarditis has healed. Surgery in the face of florid endocarditis is associated with a significantly increased risk of re-endocarditis of the prosthetic valve, paravalvular leakage, and postoperative organ failure. Despite the elevated operative risk, however, surgery is indicated even when florid endocarditis is still present if conservative therapy has failed because of a resistant causative organism, medically intractable heart failure, local spread of infection (e.g., perivalvular abscess), or the new onset of atrioventricular block. Surgery may also be indicated in cases of recurrent embolism; large, mobile vegetations threatening to give rise to emboli; and prosthesis endocarditis. Endocarditis in intravenous drug abusers is a special case. The tricuspid valve is affected in two-thirds of all patients in this group. Conservative therapy usually yields good results (8), and surgical intervention is necessary only when the valve is extensively damaged (figure 1).

Reconstructive procedures are the mainstay of surgical therapy in healed endocarditis, particularly in the case of mitral regurgitation. In florid endocarditis, on the other hand, the surgical principle of total elimination of the infectious focus is most often incompatible with the technical preconditions for successful valve reconstruction, and thus the valve is most often replaced

\section{Tricuspid stenosis and tricuspid regurgitation}

Tricuspid stenosis is rare and usually of rheumatic origin. It is often seen in combination with other valvular disturbances.

\section{Heart valve surgery in infectious endocarditis}

Important determinants of outcome include timely diagnosis, the identification of the infectious organism, and appropriately tailored antibiotic treatment. 


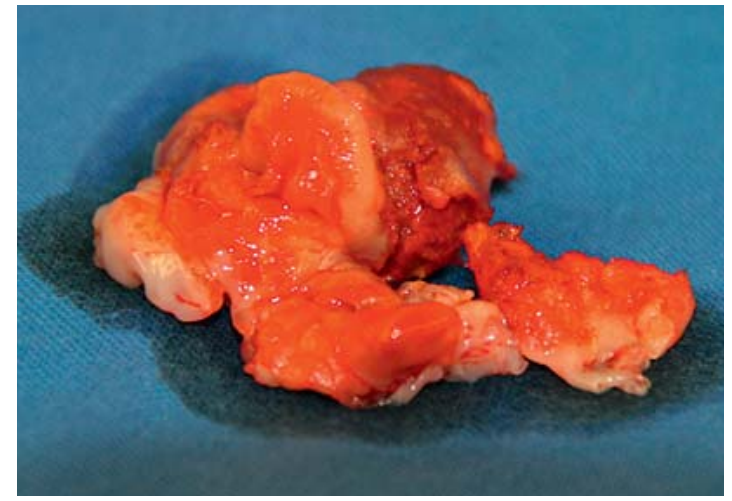

Figure 1: Excised septal leaflet of the tricuspid valve in an intravenous drug abuser with florid hepatitis $C$ and acute endocarditis. Medically intractable right-heart failure and grade III to IV tricuspid regurgitation constituted the indication for surgery. At operation, the septal leaflet was found to be overlaid with massive, florid endocarditic deposits and to be almost totally detached from the valvular annulus. The valve was replaced with a biological prosthesis. Most cases of tricuspid endocarditis in intravenous drug users can, however, be treated conservatively

in this situation. The operative lethality and perioperative morbidity are markedly higher than in elective valve replacement for patients without endocarditis, and they depend to a large degree on the condition of the individual patient (e7).

\section{Surgical techniques of heart valve replacement and reconstruction Heart valve replacement}

Heart valves can be replaced with either mechanical or biological prostheses, and biological prostheses come in two varieties, xenografts and allografts. The most common type of mechanical (artificial) valve in use today is the bi-leaflet valve, which has become the standard in most institutions because of its good hemodynamics and high mechanical reliability. The main advantage of artificial valves is that they do not undergo degenerative changes and thus have a mechanical lifespan that generally exceeds the patient's life expectancy. Artificial valve dysfunction due to material fatigue or manufacturing errors, such as occurred in the past with the Björk-Shiley Convexo-Concave (BSCC) valve, has not been encountered for some time. The main disadvantage of all artificial heart valves is the need for lifelong anticoagulation.
Biological valve prostheses are either xenografts (derived from nonhuman animals) or allografts (usually, cryopreserved heart valves obtained from organ donors). Because of their limited availability, allografts are now only rarely used to treat acquired cardiac defects. In Germany, in 2007, fewer than 50 aortic and mitral valves were replaced with allografts (1). The xenografts in use today are prepared from porcine heart valves or from bovine pericardium. There is a further distinction between xenografts that are mounted on a sewing ring (so-called stented prostheses) and those that are not (socalled stentless prostheses, which are exclusively porcine). The main advantage of all biological prostheses, both xeno- and allografts, is the low risk of thromboembolism, which makes long-term anticoagulation unnecessary. Their main disadvantage is that they are subject to degenerative calcification, which, in the long term, may necessitate reoperation. For patients who were over age 65 at the time of xenograft implantation, the rate of freedom from degenerative valve changes 15 years later is roughly $80 \%(9-11)$.

A recent advance in the area of biological prostheses has been the development of decellularized xeno- and allografts that are colonized by the patient's own endothelial cells after implantation (12-14). Valves of this type are currently undergoing clinical testing.

An alternative to aortic valve replacement with a prosthesis is replacement of the valve with the patient's own pulmonary valve (i.e., an autograft), the so-called Ross operation. The pulmonary valve, in turn, is replaced during the same procedure with an allograft or stentless xenograft.

The Ross operation constitutes an alternative to conventional valve replacement mainly for young patients who are still growing, women desiring to have children, and adults under age 65 who decline to receive a mechanical prosthesis because they do not want to be orally anticoagulated. Data from the German Ross Registry, after a mean follow-up of 3.8 years (2221 patient-years), show a valve-associated reoperation rate of $4.3 \%$ (2.9\% for the pulmonary valve autograft and $1.4 \%$ for the pulmonary valve replacement) and an operative lethality of $0.9 \%$ (15). It should be realized that patients undergoing the Ross operation tend to be much younger (age $40.6 \pm 16$ years) than those undergoing conventional aortic valve replacement.

Very recently, catheter-assisted aortic valve implantation has attracted a great deal of attention (figure 2). To date, more than 1000 patients around the

\section{Healed endocarditis}

Reconstructive operations are the most common type of surgery in patients with healed endocarditis, particularly those with mitral regurgitation.

\section{Operative methods of heart valve replacement and reconstruction}

Heart valves can be replaced with prostheses that are either mechanical or biological. Biological prostheses come in two types, xenografts and allografts. 
Figure 2:

Catheter-assisted aortic valve replacement by a transapical approach.

(a) The prosthesis is loaded in the catheter device and is ready for deployment.

(b) Intraoperative radiographic check of the position of the valve in the aorta after implantation.
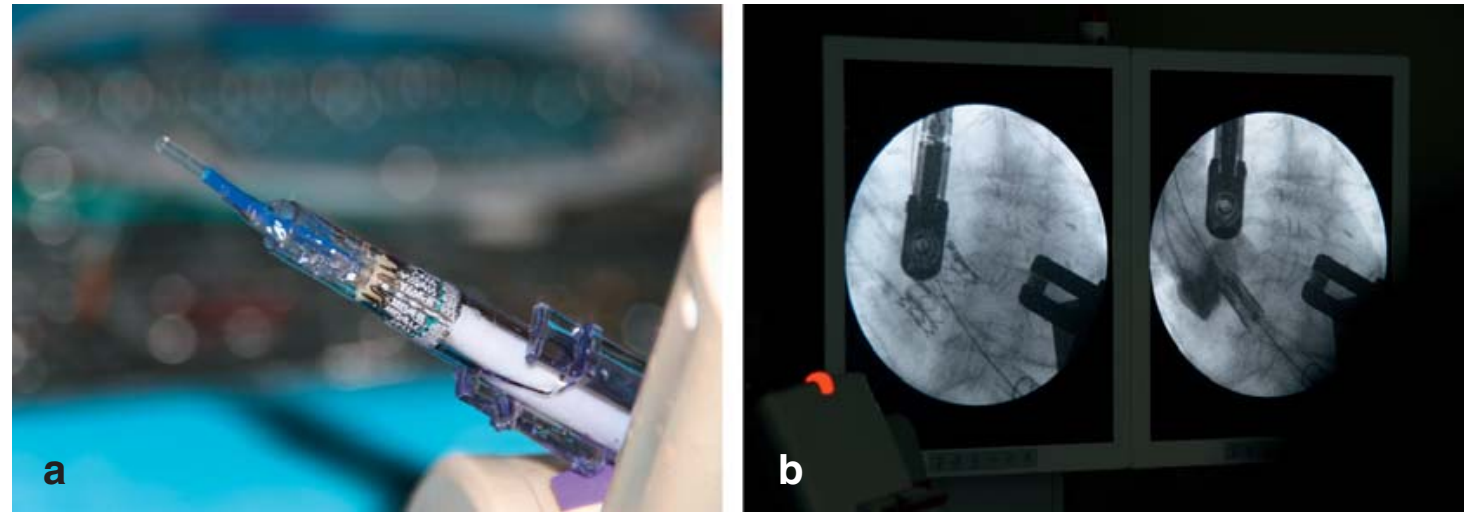

world have been treated with this technique, which is still in the clinical testing phase. It has been used so far only in high-risk patients for whom conventional surgery is contraindicated. Two approaches for catheter-assisted aortic valve implantation have become established:

1. the transapical approach, i.e., through the cardiac apex after exposure by minithoracotomy, and

2. the percutaneous transfemoral approach, by way of the femoral artery.

The transfemoral approach is contraindicated if the iliac vessels are too narrow, if the pelvic axis and/or the supra-aortic vessels display high-grade occlusive peripheral vascular disease, or in the presence of chronic aortic dissection. Implantation by either approach can generally be performed without the use of a heart-lung machine. The results to date have shown that catheterassisted valve implantation through either approach can be performed in high-risk patients with good results $(16,17)$. Open questions that can only be answered in further clinical trials concern, above all, the durability of the prostheses that are implanted in these catheter-assisted procedures, and the frequency of intervention-associated complications such as apoplexy, paravalvular leakage, and vascular dissection. At present, catheter-assisted aortic valve implantation should be considered as an alternative to conventional surgery only for patients who would be at substantially elevated operative risk.

\section{Heart valve reconstruction}

The mitral valve is by far the most commonly reconstructed heart valve. In Germany, in 2007, more than
6800 mitral valve reconstructions were performed, as compared to only about 1200 tricuspid valve reconstructions and a mere 149 aortic valve reconstructions (1).

A stenotic mitral valve can be reconstructed by commissurotomy if the commissures are fused in the absence of high-grade calcification of the leaflets. The operative technique for reconstructing a regurgitated mitral valve is more complex. Before this is done, the individual pathology of the entire mitral valve apparatus must be thoroughly analyzed. The Carpentier classification has become well established for this purpose (18). It combines functional with anatomical aspects and allows the surgeon to plan the reconstruction in detail. Previously, the assessment could only be performed intraoperatively on the open heart, but TEE now enables the surgeon to plan the reconstruction preoperatively. Depending on the findings, a variety of techniques can be used to reconstruct the leaflets and chordae, including the use of artificial chordae made of Gore-Tex, quadrangular resection, and other techniques $(19,20)$. Annuloplasty, i.e., reshaping of the mitral valvular ring, is practically always performed as a component of reconstruction (figure 3). A minimally invasive approach by way of a small right thoracotomy has been in use for a number of years.

Tricuspid regurgitation is due, in most cases, to primary or secondary dilatation of the ring. Thus, annuloplasty usually suffices for valve reconstruction in this position.

Aortic valve reconstruction has attracted increased attention recently. Aortic valve replacement is still the treatment of choice for calcific aortic stenosis, because

\footnotetext{
The Ross operation-mainly an option for

- young, still growing patients,

- women that want to bear children,

- adults under age 65 that prefer not to receive a mechanical prosthetic valve because they do not want oral anticoagulation.
}

\section{Mitral valve reconstruction}

The mitral valve is by far the most commonly reconstructed heart valve. 
the reconstruction of calcific valves has been found to yield poor long-term results, but reconstruction can be successful in certain types of aortic regurgitation (21). Purely valvular aortic regurgitation must be distinguished from regurgitation in the presence of aortic aneurysm and dissection of the aortic root; the latter conditions cause aortic regurgitation by dilating the aortic ring. The valves themselves are usually normal in such patients, so that the aortic root can be reconstructed with preservation of the valve (the David or Yacoub operation).

\section{Recommendations for treatment in the aftermath of heart valve surgery}

The outpatient treatment of patients who have undergone heart valve surgery has three main aspects:

- oral anticoagulation,

- endocarditis prevention, and

- echocardiographic follow-up.

\section{Oral anticoagulation}

In principle, all patients that have received a mechanical (artificial) heart valve prosthesis should be orally anticoagulated for life (22). For modern, bi-leaflet prostheses, the target INR values are 2.5 for aortic and 3.5 for mitral and tricuspid valves. In patients whose compliance is adequate, the rate of complications of oral anticoagulation can be significantly reduced by INR self-management (e8). After a biological prosthesis is implanted, anticoagulation is generally considered necessary for the first three months after surgery, during which the implanted foreign material (sutures, felt, and valvular ring) is epithelialized. Alternatively, for biological prostheses in the aortic position, platelet aggregation inhibitors can be given for three months instead of oral anticoagulation $(23,24)$. Similarly, after heart valve reconstruction, oral anticoagulation is needed for the first three months after surgery. Oral anticoagulation can, of course, be indicated by another condition, such as atrial fibrillation, regardless of the type of prosthesis or valvular reconstruction.

\section{Endocarditis prevention}

According to the newly issued guidelines of the American Heart Association and the position paper of the German Cardiac Society (2007), endocarditis prevention is no longer obligatory for a considerable number of diagnoses and procedures (25, e9). It is still obligatory, however, for

\section{Current techniques of mitral valve reconstruction \\ - Mitral stenosis: commissurotomy \\ - Mitral regurgitation: artificial chordae made of \\ Gore-Tex, quadrangular resection, annuloplasty}

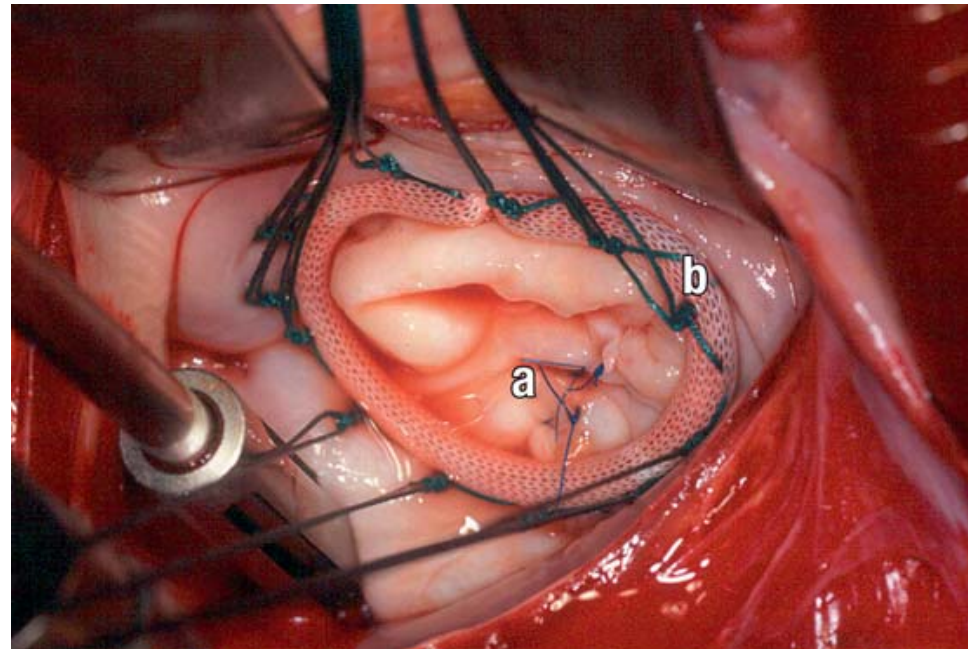

Figure 3: Intraoperative view of a reconstructed mitral valve (indication: mitral regurgitation). Preoperatively, the posterior leaflet was prolapsed because of a chordal tear. The corresponding segment of the posterior leaflet was removed by quadrantectomy (a), the leaflet was reconstructed, and a flexible annuloplasty ring was implanted (b).

- patients with heart valve prostheses, regardless of whether these are biological or mechanical;

- patients with a prior history of endocarditis;

- patients that have received heart transplants and have a valvulopathy.

For these groups of patients, endocarditis prevention is still recommended for any dental procedure for the rest of their lives, regardless of whether a manifest infection is present. In the position paper of the German Cardiac Society, endocarditis prevention even in the absence of a manifest infection is recommended in the first six months after surgery for all patients that have undergone heart valve reconstruction with prosthetic material (e.g., an annuloplasty ring). This recommendation is at variance with the guidelines of the American Heart Association, according to which patients in this group should be given endocarditis prevention for any dental procedure for the rest of their lives (e9). In any case, patients in all of the groups defined above should definitely receive endocarditis prevention for any procedure involving the respiratory tract, such as adenectomy or tonsillectomy (though this is no longer considered obligatory for a purely diagnostic bronchoscopy). Endocarditis prevention is no longer recommended for diagnostic endoscopy of the gastrointestinal or genitourinary tract, as long as

\section{Postoperative care}

In principle, all patients with a mechanical heart valve prosthesis (artificial valve) must be orally anticoagulated for life. 
there is no manifest infection. As soon as an infection is manifest, however, endocarditis prevention is indicated.

\section{Follow-up echocardiography}

Alongside physical examination and ECG, echocardiography is important in the postoperative follow-up of patients who have undergone heart valve surgery. The main purpose of echocardiography is to assess the function of the prosthetic or reconstructed valve. It is important that any paravalvular leaks arising in the patient's postoperative course should be detected; these may arise either early, as a result of technical problems during surgery, or late, e.g., because of prosthesis endocarditis. If a biological prosthesis has been implanted, echocardiography is used for long-term follow-up of any potential degenerative structural changes, which may lead to valvular stenosis or regurgitation. Just as importantly, echocardiography can provide early evidence of thrombus formation, particularly in the case of artificial valves after phases of inadequate anticoagulation. The first outpatient followup study should be performed about three months after surgery (22).

\section{Conflict of interest statement \\ The authors declare that they have no conflict of interest as defined by the guidelines of the International Committee of Medical Journal Editors.}

Manuscript received on 16 December 2008; revised version accepted on 3 March 2009.

Translated from the original German by Ethan Taub, M.D.

\section{REFERENCES}

1. Gummert JF, Funkat A, Beckmann A et al.: Cardiac Surgery in Germany during 2007: A report on behalf of the German Society for Thoracic and Cardiovascular Surgery. Thorac Cardiov Surg 2008; 56: 328-36

2. Daniel WG, Baumgartner H, Gohlke-Bärwolf $\mathrm{C}$ et al.: Klappenvitien im Erwachsenenalter. Clin Res Cardiol 2006; 95: 620-41.

3. Sievers HH, Schmidtke C: A classification system for the bicuspid aortic valve from 304 surgical specimens. J Thorac Cardiovasc Surg 2007; 133: 1226-33.

4. Franke UFW, Wahlers T: Patientenadaptierte chirurgische Therapie von Aortenklappenfehlern. Dtsch Arztebl 2004; 101(16): A1092-8.

5. Mohr FW, Fabricius AM, Falk V et al.: Curative treatment of atrial fibrillation with intraoperative radiofrequency ablation: short-term and midterm results. J Thorac Cardiovasc Surg 2002; 123: 919-27.

6. Gillinov AM: Ablation of atrial fibrillation with mitral valve surgery Curr Opin Cardiol 2005; 20: 107-14
7. Fritz MKH, Deneke T, Reber D, Falsafi MAK, Laczkovics AM: Bedeutung der Rhythmuschirurgie für die Behandlung des Vorhofflimmerns. Dtsch Arztebl 2006; 103(28-29): A1965-70.

8. Naber CK, Bauhofer A, Block M et al.: S2-Leitlinie zur Diagnostik und Therapie der infektiösen Endokarditis. Z Kardiol 2004; 93: 1005-21.

9. Bottio T, Rizzoli G, Thiene G, Nesseris G, Casarotto D, Gerosa G: Hemodynamic and clinical outcomes with the Biocor valve in the aortic position: an 8-year experience. J Thorac Cardiovasc Surg 2004; 127: 1616-23.

10. Bortolotti U, Milanao A, Mossuto E, Mazzaro E, Thiene G, Casarotto $D:$ Porcine valve durability: a comparison between Hancock standard and Hancock II bioprothesis. Ann Thorac Surg 1995; 60: 216-20.

11. Rizzoli G, Bottio T, Thiene G, ToscanoG, Casarotto D: Long-term durability of the Hancock II porcine bioprothesis. J Thorac Cardiovasc Surg 2003; 126: 66-74

12. Lichtenberg A, Tudorache I, Cebotari S et al.: Preclinical testing of tissue-engineered heart valves re-endothelialized under simulated physiological conditions. Circulation 2006; 114: I-559-65.

13. Bechtel JF, Stierle U, Sievers HH: Fifty-two months' mean follow-up of decellularized SynerGraft-treated pulmonary valve allografts. J Heart Valve Dis 2008; 17: 98-104

14. Dohmen PM, Lembcke A, Holinski S et al.: Mid-term clinical results using a tissue-engineered pulmonary valve to reconstruct the right ventricular outflow tract during the Ross procedure.

15. Sievers HH, Stierle U, Hanke T et al.: Die Ross-Operation-eine Therapieoption bei Aortenklappenerkrankungen: Ergebnisse des Deutschen Ross-Registers. Dtsch Arztebl 2005; 102(30): A 2090-7.

16. Walther T, Simon P, Dewey T et al.: Transapical minimally invasive aortic valve implantation: multicenter experience. Circulation 2007; 116: $240-5$.

17. Rodes-Cabau J, Dumont E, de LaRochelliere R et al.: Feasibility and initial results of percutaneous aortic valve implantation including selection of the transfemoral or transapical approach in patients with severe aortic stenosis. Am J Cardiol 2008; 102: 1240-6.

18. Carpentier A, Deloche A, Dauptain J et al.: A new reconstructive operation for correction of mitral and tricuspid insufficiency. J Thorac Cardiovasc Surg 1971; 61: 1-13.

19. V Oppell UO, Mohr FW: Chordal replacement for both minimally invasive and conventional mitral valve surgery using premeasured gore-tex loops. Ann Thorac Surg 2000; 70: 2166-8.

20. Seeburger J, Kuntze T, Mohr FW: Gore-tex chordoplasty in degenerative mitral valve repair. Semin Thorac Cardiovasc Surg 2007; 19 : $111-5$.

21. Misfeld M, Bechtel M, Sievers HH: Types of reconstructive surgery of the aortic valve. J Cardiovasc Surg 2007; 48: 781-90.

22. Butchart EG, Gohlke-Bärwolf C, Antunes MJ et al.: Recommendations for the management of patients after heart valve surgery. Eur Heart $\mathrm{J}$ 2005; 26: 2463-71.

23. Gherli T, Colli A, Fragnito $\mathrm{C}$ et al.: Comparing warfarin with aspirin after biological aortic valve replacement: a prospective study. Circulation 2004: 110: 496-500

\section{Follow-up echocardiography}

Echocardiography is performed in follow-up to assess the function of the prosthetic or reconstructed valve. It is important to detect any paravalvular leaks that may arise over the patient's further course. 
24. Brueck M, Kramer W, Vogt P, Steinert N et al.: Antiplatelet therapy early after bioprosthetic aortic valve replacement is unnecessary in patients without thromboembolic risk factors. Eur J Cardiothorac Surg 2007; 32: 108-12.

25. Naber CK, Al-Nawas B, Baumgartner $\mathrm{H}$ et al.: Prophylaxe der infektiösen Endokarditis. Kardiologe 2007; 1: 243-250.

\section{Corresponding author}

PD Dr. med. Hans Joachim Geißler

Abteilung für Herz- und Gefäßchirurgie

Chirurgische Klinik

Universitätsklinikum Freiburg

Hugstetterstr. 55, 79106 Freiburg, Germany

joachim.geissler@uniklinik-freiburg.de

www.aerzteblatt-international de/ref1309

\section{Further Information on GME}

This article has been certified by the North Rhine Academy for Postgraduate and Continuing Medical Education.

Deutsches Ärzteblatt provides certified continuing medical education (CME) in accordance with the requirements of the Chambers of Physicians of the German federal states (Länder). CME points of the Chambers of Physicians can be acquired only through the Internet by the use of the German version of the CME questionnaire within 6 weeks of publication of the article, i.e., by 8 May 2009. See the following website: cme.aerzteblatt.de

Participants in the CME program can manage their CME points with their 15-digit "uniform CME number" (einheitliche Fortbildungsnummer, EFN). The EFN must be entered in the appropriate field in the cme.aerzteblatt.de website under "meine Daten" ("my data"), or upon registration. The EFN appears on each participant's CME certificate.

The solutions to the following questions will be published in volume 21/2009. The CME unit "Aftercare for Patients With Transplanted Organs" (volume 9/2009) can be accessed until 10 April 2009.

For volume 17/2009 we plan to offer the topic "Disorders of Pubertal Development."

Solutions to the CME questionnaire in volume 5/2009:

Nau R, Christen HJ, Eiffert H: Lyme Disease-Current State of Knowledge:1c, 2c, 3a, 4b, 5d, 6c, 7a, 8e, 9a, 10a 


\section{Please answer the following questions to participate in our certified Continuing Medical Education program. Only one answer is possible per question. Please select the answer that is most appropriate.}

\section{Question 1}

How is tricuspid valvular endocarditis treated in the majority of affected patients that are intravenous drug abusers?

a) Operatively, with tricuspid valve reconstruction

b) With a medicated stent

c) Conservatively, with antibiotics

d) With the implantation of a transvenous cardiac pacemaker

e) Operatively, with tricuspid valve replacement

\section{Question 2}

What does the current position paper of the German Cardiac Society (2007) recommend for the prophylaxis of infectious endocarditis?

a) Patients with valvular prostheses should be given endocarditis prophylaxis only in the presence of a manifest infection.

b) Patients with valvular prostheses should be given endocarditis prophylaxis for any dental procedure for the rest of their lives.

c) Patients with valvular prostheses should be given endocarditis prophylaxis for gastroscopy even in the absence of manifest infection

d) Patients with valvular prostheses should be given endocarditis prophylaxis for cystoscopy even in the absence of manifest infection

e) Patients with valvular prostheses should be given endocarditis prophylaxis for colonoscopy even in the absence of manifest infection

Question 3

What is the desired INR value for patients with a mechanical aortic valvular prosthesis?
a) 1.0
b) 1.5
c) 2.0
d) 2.5
e) 3.0

\section{Question 4}

For what group of patients does the Ross procedure (aortic valve replacement with a pulmonic valve autograft) constitute a reasonable alternative to prosthetic valve replacement?

a) Women that want to have children

b) Patients aged 70 or older

c) Patients that already have an artificial mitral valve

d) Patients already being treated with vitamin $\mathrm{K}$ antagonists

e) Patients with severe pulmonic regurgitation

Question 5

For which patients with aortic regurgitation is there a class I recommendation for surgery?

a) Asymptomatic patients with healed endocarditis

b) Asymptomatic patients with LVEF $<50 \%$ and end-systolic LV diameter $>50 \mathrm{~mm}$

c) Asymptomatic patients with LVEF $>60 \%$ and end-systolic LV diameter $<45 \mathrm{~mm}$

d) Asymptomatic patients with LVEF $>60 \%$, if valve reconstruction is possible

e) Asymptomatic patients with LVEF > 50\% and end-systolic LV diameter $<50 \mathrm{~mm}$

\section{Question 6}

For which patients with tricuspid regurgitation is surgery indicated?

a) Patients with mild tricuspid regurgitation

b) Patients with mild tricuspid regurgitation and tricuspid stenosis with a mean gradient $<5 \mathrm{~mm} \mathrm{Hg}$

c) Patients with moderate tricuspid regurgitation and atrial fibrillation

d) Patients with severe tricuspid regurgitation and severe right heart failure

e) Patients with severe tricuspid regurgitation without clinical signs of right heart failure

\section{Question 7}

Which of the following is an important aspect of the postoperative care of a patient who has undergone aortic valve replacement with a biological prosthesis?

a) Oral anticoagulation is needed for life.

b) Oral anticoagulation should be given for six months after surgery.

c) Oral anticoagulation or platelet aggregation inhibitors should be given for three months after surgery.

d) Reoperation will be needed in six to eight years, at most, because of breakdown of the prosthesis.

e) No endocarditis prophylaxis is necessary.

\section{Question 8}

When is valvuloplasty indicated in a patient with severe mitral stenosis?

a) In a symptomatic patient with a markedly calcified mitral valve

b) In a symptomatic patient with thrombi in the left atrium

c) In a symptomatic patient with marked concomitant mitral regurgitation

d) In a symptomatic patient with concomitant aortic stenosis for which surgery is indicated

e) In a symptomatic patient with a mitral valve opening area $<1.5 \mathrm{~cm}^{2}$

\section{Question 9}

What is the role of annuloplasty (reshaping of the valvular annulus) in mitral valve surgery?

a) Annuloplasty is an important component of mitral valve reconstruction.

b) Mitral valve replacements are often reinforced with valvuloplasty in order to increase the durability of the prosthesis.

c) Annuloplasty is an older technique that is now only rarely used in mitral valve reconstruction procedures.

d) Annuloplasty of the mitral valve is only indicated in patients with atrial fibrillation.

e) Annuloplasty had now been replaced by the use of artificial chordae made of Gore-Tex.

\section{Question 10}

Which of the following are clinically established options for biological valve replacement?

a) Prostheses made of bovine pericardium

b) Prostheses made of porcine heart valves

c) Cryopreserved human heart valves from organ donors (allografts)

d) Pulmonary valve autografts (the Ross procedure)

e) All of the above 
CONTINUING MEDICAL EDUCATION

Heart Valve Surgery Today

Indications, Operative Technique, and Selected Aspects of

Postoperative Care in Acquired Valvular Heart Disease

Hans Joachim Geißler, Christian Schlensak, Michael Südkamp, Friedhelm Beyersdorf

\section{E-REFERENCES}

e1. Vahanian A, Baumgartner H, Bax J et al.: Guidelines on the management of valvular heart disease. The task force on the mangement of valvular heart disease of the European Society of Cardiology: Eur Heart J 2007; 28: 230-268.

e2. Bonow RO, Carabello BA, Kanu C et al.: ACC/AHA 2006 guidelines for the management of patients with valvular heart disease: a report of the American College of Cardiology/American Heart Association Task Force on Practice guidelines: developed in collaboration with the Society of Cardiovascular Anesthesiologists: endorsed by the Society for Cardiovascular Angiography and Intervention and the Society of Thoracic Surgeons: Circulation 2006; 114(5): e84-23.

e3. Faggiano P, Ghizzoni G, Sorgato A, Sabatini T, Simoncelli U, Gardini A, Rusconi C: Rate of progression of valvular aortic stenosis in adults. Am J Cardiol 1992; 70: 229-33.

e4. deFilippi CR, Willett DL, Brickner ME, Appleton CP, Yancy CW, Eichhorn EJ, Grayburn PA: Usefulness of dobutamine echocardiography in distinguishing severe from nonsevere valvular aortic stenosis in patients with depressed left ventricular function and low transvalvular gradients . Am J Cardiol 1995; 75: 191-4.

e5. Mehta RH, Bruckmann D, Das S et al.: Implications of increased left ventricular mass index on in-hospital outcomes in patients undergoing aortic valve surgery. J Thorac Cardiovasc Surg 2001; 122: 919-28.

e6. Ray AA, Buth KJ, Sullivan JA, Johnstone DE, Hirsch GM: Waiting for cardiac surgery. Results of a risk stratified queuing process. Circulation 2001; 104[Suppl I]: 192-8.

e7. McKay G, Bunton R, Galvin I, Shaw D, Singh H: Infective endocarditis—a twelve year surgical outcome series. N Z Med J 2002; 115: 124-26.

e8. Koertke H, Minami K, Boethig D, et al.: INR self-management permits lower anticoagulation levels after mechnical heart valve replacement. Circulation 2003; 108[Suppl II]: II75-8.

e9. Wilson W, Taubert KA, Gewitz M et al.: Prevention of infective endocarditis. Guidelines from the American Heart Association. A guideline from the American Heart Association Rheumatic Fever, Endocarditis, and Kawasaki Disease Committee, Council on Cardiovascular Disease in the Young, and the Council on Clinical Cardiology, Council on Cardiovascular Surgery and Anesthesia, and Quality of Care and Outcomes Research Interdisciplinary Working Group. Circulation 2007; 116: 1736-54. 